\title{
Natural convection heat transfer from a vertical plate to high permeability porous media: an experiment and an approximate solution
}

\author{
M. KAVIANY \\ Department of Mechanical Engineering and Applied Mechanics, University of Michigan, \\ Ann Arbor, MI 48109, U.S.A. \\ and \\ M. MITTAL \\ Department of Mechanical Engineering, University of Wisconsin-Milwaukee, \\ Milwaukee, WI 53201, U.S.A. \\ (Received 21 April 1986 and in final form 25 July 1986)

\begin{abstract}
The heat transfer rate from an isothermal vertical plate placed next to saturated high permeability porous media is studied experimentally and analytically. The media used are polyurethane foams saturated with air. An integral method is applied in predicting the heat transfer rate by including the non-Darcy effects, which are expected to be significant for high permeabilities and high Rayleigh numbers. Good agreement is found between the experimental and predicted results except when the permeability is relatively low and the Péclet number becomes very small. Although some of the permeabilities encountered are large, for the experimental conditions considered in this study the Rayleigh numbers are not very high; therefore, the non-Darcy effects are not significant.
\end{abstract}

\section{INTRODUCTION}

IN HIGH permeability media the boundary and inertia effects, not included in Darcy's model, may alter the velocity fields and heat transfer characteristics. Therefore, it is necessary to determine the parameters defining the regimes over which these effects are important. For forced convection flows this has been done [1-4], and it was shown that for Reynolds numbers based on a particle or pore size larger than unity a velocitysquared term must be added $[1,2]$. Also, the viscous boundary layer develops very rapidly and then remains constant $[3,4]$, and the Nusselt number decreases when the inertia and boundary effects become significant $[3,4]$.

The vertical flat plate natural convection flow is treated in ref. [5] where a boundary layer and Darcy's approximations are applied and in refs. [6, 7] where the effects of axial conduction and the transverse pressure gradient are included (these effects were determined to be negligible for isothermal plates). The results show that the Nusselt number is independent of Prandtl number and depends on the RayleighDarcy number to the $1 / 2$ power. These are in contrast to the case where no solid matrix is present, which results in Prandtl number dependency and a 1/4 power for the Rayleigh number.

In refs. $[8,9]$ the effect of the velocity-squared term (called the non-Darcy effect), which is based on experimental results for forced convection [2], was included in the analysis. The results, which allow for velocity slip at the rigid boundary, show that the Nusselt number decreases as the non-Darcy effects become more pronounced and that it does not depend on the Prandtl number.

The boundary effect was included in ref. [10] and it was found that this results in a smaller Nusselt number, but this difference decreased as the Rayleigh number increased. Recent efforts [11] have included the effects of the inertia, boundary and the velocitysquared terms. The results showed that both the boundary term and velocity-squared term reduced the heat transfer rate.

Laminar natural convection heat transfer from vertical surfaces to saturated porous media has also been studied experimentally $[10,12]$. Table 1 shows the experimental conditions used in this and other experimental studies. The objective of this study was to examine the validity of the available predictions for high permeability porous media and over a large range of $\xi_{x}$. In some cases researchers have used water as the saturating fluid. Using water reduces the heat losses (through the back of the heated plate), it requires a closed system; therefore, the heated water must be cooled before it returns to the heated wall. In consequence these experiments are generally cavity problems at high Rayleigh numbers.

In this study an integral approximation method, as was previously applied to Darcy's model [13], is applied to the local volume-averaged conservation equations which include the non-Darcy effects. The integral method is relatively accurate and does not 


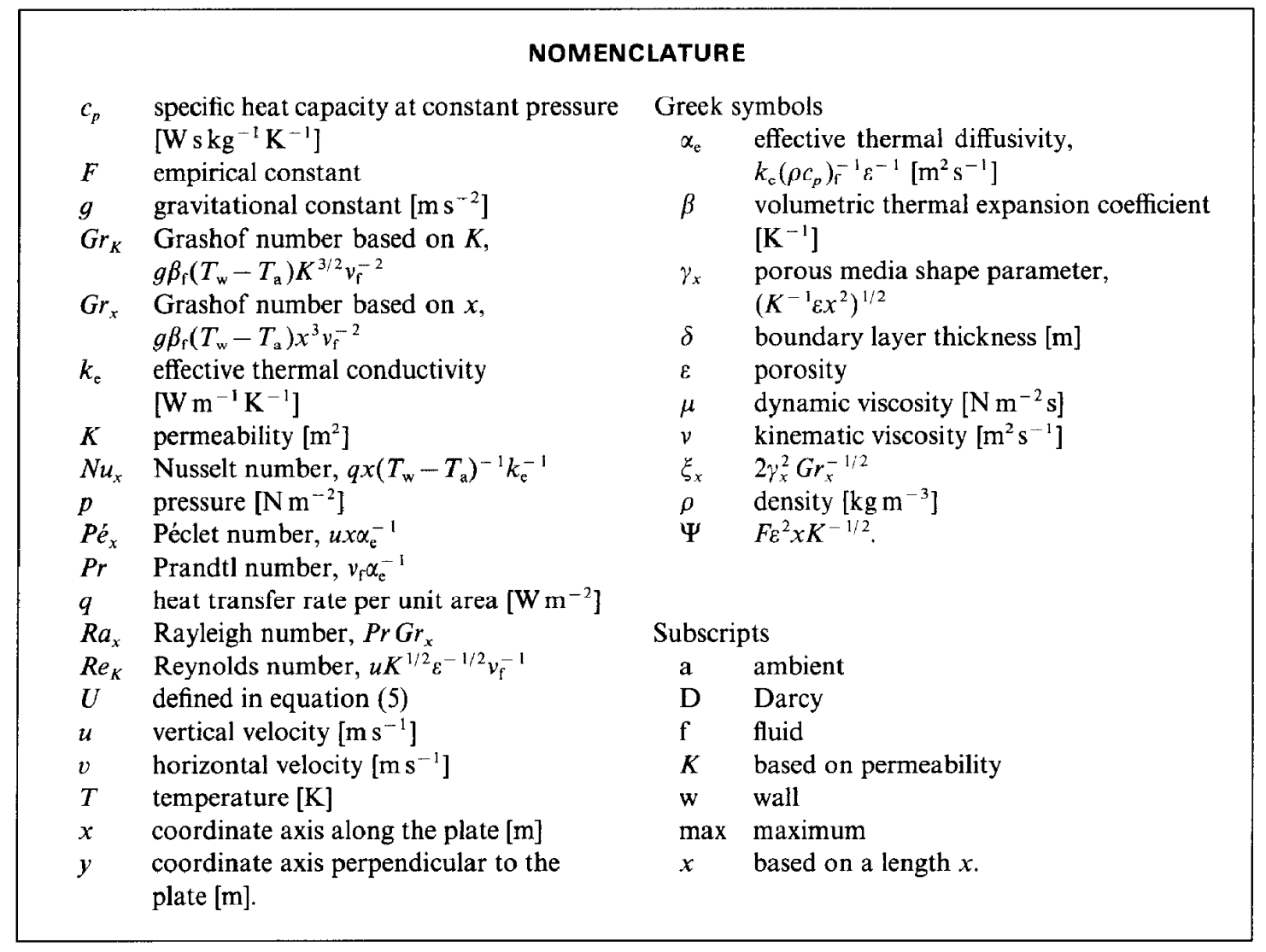

Table 1. A comparison of the experimental conditions

\begin{tabular}{|c|c|c|c|c|c|c|c|}
\hline & Fluid & Rigid matrix & $\operatorname{Pr}_{\mathrm{e}}$ & $\begin{array}{c}K \\
\left(\mathrm{~m}^{2}\right)\end{array}$ & $\gamma_{x}^{2}$ & $R a_{x}$ & $\xi_{x}$ \\
\hline Ref. [5] & water & glass beads & 2.4 & $\begin{array}{l}3.5 \times 10^{-10} \\
1.2 \times 10^{-9}\end{array}$ & $\begin{array}{l}2.5 \times 10^{6}- \\
2.4 \times 10^{8}\end{array}$ & $\begin{array}{l}1.4 \times 10^{8} \\
5.1 \times 10^{11}\end{array}$ & $132-672$ \\
\hline $\begin{array}{l}\text { Ref. [6] } \\
\quad \text { (inclined) }\end{array}$ & water & glass beads & 2.4 & $5.2 \times 10^{-9}$ & $\begin{array}{l}5.6 \times 10^{6}- \\
1.1 \times 10^{7}\end{array}$ & $\begin{array}{l}1.0 \times 10^{9}- \\
1.0 \times 10^{11}\end{array}$ & $91-660$ \\
\hline This study & air & $\begin{array}{l}\text { polyurethane } \\
\text { foam }\end{array}$ & $0.33-0.60$ & $\begin{array}{l}3.7 \times 10^{-9} \\
1.6 \times 10^{-7}\end{array}$ & $\begin{array}{l}6.1 \times 10^{2}- \\
3.3 \times 10^{6}\end{array}$ & $\begin{array}{l}1.6 \times 10^{3}- \\
5.0 \times 10^{6}\end{array}$ & $17-2249$ \\
\hline
\end{tabular}

require a change of scale in transition from the Darcy to non-Darcy regime as required by the numerical schemes [11], and it is computationally very economical and stable for a large range of parameters. Also, this method leads to some closed form solutions. However, its application is limited to Prandtl numbers near unity. As a result of the analysis the Nusselt number for the case of an isothermal plate is determined.

\section{EXPERIMENT}

\subsection{Vertical plate and porous media}

The plate assembly consists of the following: a marinite block $(30 \times 30 \times 5 \mathrm{~cm})$, with a rectangular depression in the center of the $30 \times 30 \mathrm{~cm}$ face, housed the heater plate assembly. In this depression were situated the following-an insulation foam (ensures that the strip heaters make good contact with the back of the aluminum plate), the strip heaters (ten in number), an aluminum plate $(20 \times 14 \times 0.3 \mathrm{~cm})$ and fasteners (to keep the aluminum plate in its place).

The voltages across the heaters were varied independently by means of individual signal conditioning circuits. The aluminum surface temperature was measured by ten thermocouples with their beads centered at a distance of roughly $1 \mathrm{~mm}$ from the surface.

The porous media were polyurethane foams of $30 \times 30 \times 46 \mathrm{~cm}$. These media had five different permcabilitics (or number of pores per inch, ppi) namely $10,45,60,80$ and $100 \mathrm{ppi}$. The porosity for all of the foams was measured and was nearly 0.98 .

Each foam was placed against the $30 \times 30 \mathrm{~cm}$ face 
of the marinite block, so that the face of the aluminum plate was covered entirely. Thermocouples were placed at various vertical and horizontal locations and all were running along the isothermal line. It is very important that approximately the first $3 \mathrm{~cm}$ of the thermocouple wire did not pass through a large temperature gradient. For most cases the thermocouples were located at $2.1,5.1,8.1$ and $11.1 \mathrm{~cm}$ from the bottom edge of the aluminum plate and were centered laterally on the plate.

Fiberglass insulation was placed around the marinite block and thermocouples were placed in various locations on the surface of the marinite and fiberglass in order to determine and reduce the heat losses. A data acquisition system consisting of a HP 3456A voltmeter, a HP 3497A scanner, and a HP 9817 computer was used.

The voltage across each heater was adjusted to achieve a uniform temperature across the plate. This was done at intervals of $45-60$ min until a steady state was reached. Steady states were achieved in about $12-24 \mathrm{~h}$.

\subsection{Measurement of permeability}

Permeability of the foams was measured using a setup consisting of a $1.60 \mathrm{~cm}$ plexiglas tube with an inner diameter of $2.54 \mathrm{~cm}$ and a pressure tap at a distance of $68 \mathrm{~cm}$ from one end, a flowmeter, a water manometer, and two cylindrical pieces of polyurethane foam (samples) each $2.54 \mathrm{~cm}$ in diameter and $30 \mathrm{~cm}$ in length.

One end of the tube was open and the foam samples were placed between this end and the tap. The other end of the tube was connected to the air supply through the flowmeter. The unfilled portion of the tube acted as a diffuser. The tap was connected to the water manometer.

The experiments were conducted as follows :

(i) The flow rate was gradually increased to 5 $1 \mathrm{~min}^{-1}$ (the minimum readable value on the flowmeter). The reading of the water manometer was taken at this flow rate.

(ii) The flow rate was increased by a step of 5 $1 \min ^{-1}$ and the reading of the water manometer was taken again.

(iii) Step (ii) was repeated until the flow rate reached a value of $601 \mathrm{~min}^{-1}$.

(iv) After step (iii) the flow rate was gradually decreased in steps of $51 \mathrm{~min}^{-1}$ and the manometer reading taken again. This step was carried out to check consistency in results, which were found to be consistent.

(v) Steps (i)-(iv) were repeated using only one foam piece. This was done in order to detect any possible significant entrance or end effects, none of which were found. These steps were repeated for foams of different permeabilities (i.e. 10, 45, 60, 80 and $100 \mathrm{ppi}$ ).

Since very low flow rates could not be measured with this flowmeter, the permeability was calculated using a correlation which includes the second order effect [3], i.e.

$$
\frac{\mathrm{d} p}{\mathrm{~d} x}=\frac{\mu_{\mathrm{f}}}{K} u_{\mathrm{D}}-\rho_{\mathrm{f}} \frac{F}{K^{1 / 2}} u_{\mathrm{D}}^{2} .
$$

Figure 1 shows the results. The intercept of the curve was taken as $1 / K$ and then $F$ was calculated from the slope.

\subsection{Thermal conductivity}

Figure 2 shows the manufacturer $\dagger$ measured effective thermal conductivity for the foams in air. Although the porosity for all ppi is nearly 0.98 , the effective thermal conductivity decreases with ppi; therefore, the simple volume average of the thermal conductivities does not apply to these foams (at least at lower ppi).

\subsection{Source of errors}

Although the magnitude of errors cannot be determined with sufficient confidence, the possible sources of error are given below.

(a) Variation in the ppi. The number of pores per inch is about $\pm 10 \%$ of the value suggested by the manufacturer. This affects the permeability and thermal conductivity values.

(b) Locations of the thermocouple bead. It is important to place the thermocouple as close to the heated plate as possible in order to obtain accurate heat transfer rates using the slope of the $T(y)$ curve at $y=0$. However, it was not possible to penetrate the thermocouples and their stainless steel casings through the foams such that they remained exactly parallel to the heated face of the foams. This was especially true for those thermocouples placed very close to the heated surface of the foam.

(c) Thermocouple wire. If the initial portion of the thermocouple wire passes through a region of significant temperature gradient, the readings become erroneous. Therefore, the thermocouple wires must be laid along the isothermal lines.

\section{(d) Foam block.}

(i) The foam blocks were of finite size and the boundary conditions at the other five surfaces were not controlled. This causes two concerns. One is that the boundary layer must be well situated inside the foam. This was true for most of the experiments. The other is that the axial condition which is neglected in the boundary layer analysis will become important for low Péclet numbers. $\ddagger$ Based on the predictions the maximum boundary layer thickness ranged from 7.9 to $33 \mathrm{~cm}$, the maximum velocity ranged from 0.03 to $0.9 \mathrm{~cm} \mathrm{~s}^{-1}$ and the maximum $P e ́$ ranged from 0.88 to 15.96. Therefore, at low $P \dot{e}_{x}$, one expects the finiteness of the foam height (through its thermal and hydro-

$\dagger$ Scott, Foam Division, Eddystone, Pennsylvania.

$¥$ This is taken to be for distances far removed from the leading edge. The leading edge effects are not considered here. 


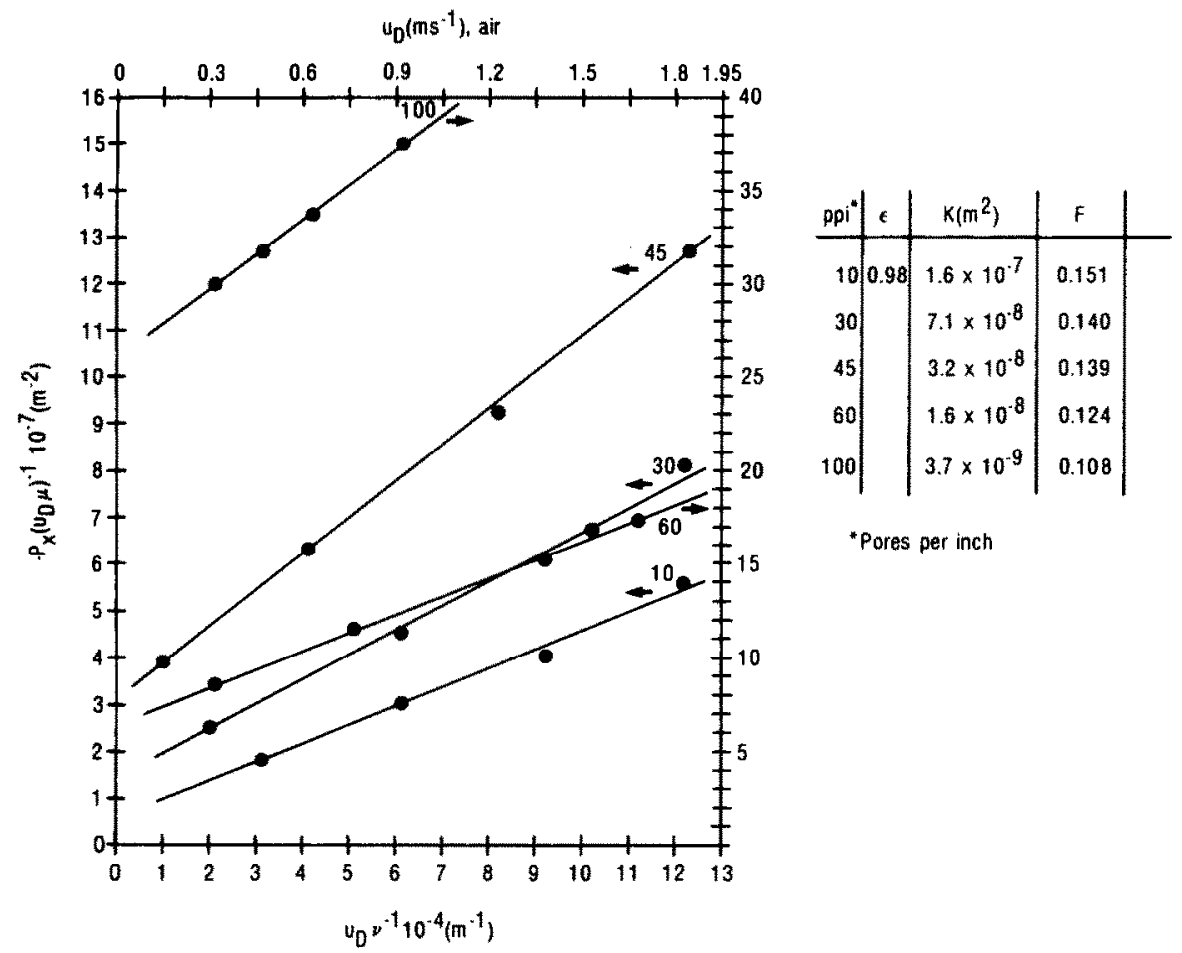

FrG. 1. The measured pressure drops for various foams. Also shown are the deduced permeabilities.

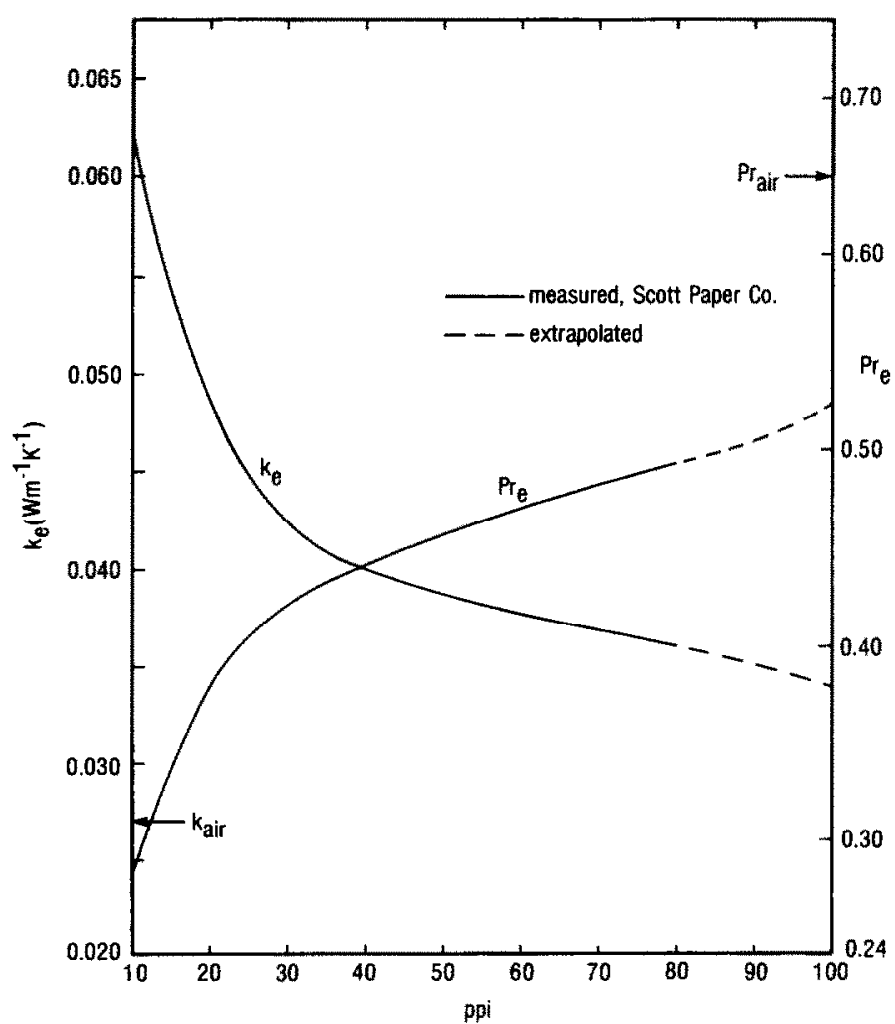

Fig. 2. The measured effective thermal conductivity for various foams saturated with air. Also shown is the effective Prandtl number. 
dynamic boundary condition) to affect the upstream heat transfer results.

(ii) In a few locations where the thermocouples were inserted, extra voids were produced. However, since the voids caused were small and the foams were elastic enough such that these voids were further reduced after the withdrawal of the thermocouples, this effect is not considered significant.

\section{GOVERNING EQUATIONS}

Consider a coordinate system with $x$ along the semiinfinite plate and $y$ perpendicular to it. By assuming a linear equation of state, for a two-dimensional, steady-state, buoyancy-driven boundary layer flow in porous media we have the following volume-averaged equations $\uparrow[3]$

$$
\begin{gathered}
\frac{\partial u}{\partial x}+\frac{\partial v}{\partial y}=0 \\
\rho_{\mathrm{f}} u \frac{\partial u}{\partial x}+\rho_{\mathrm{f}} v \frac{\partial u}{\partial y}= \\
=\mu_{\mathrm{f}} \frac{\partial^{2} u}{\partial y^{2}}-K^{-1} \varepsilon \mu_{\mathrm{f}} u \\
+\rho_{\mathrm{f}} \beta_{\mathrm{f}} g\left(T-T_{\mathrm{a}}\right)-F_{\varepsilon}^{2} K^{-1 / 2} \rho_{\mathrm{f}} u^{2} \\
u \frac{\partial T}{\partial x}+v \frac{\partial T}{\partial y}=\alpha_{\mathrm{e}} \frac{\partial^{2} T}{\partial y^{2}} .
\end{gathered}
$$

The boundary conditions are :

$$
\begin{array}{ll}
T=T_{\mathrm{w}} & \text { at } y=0 \\
T=T_{\mathrm{a}} & \text { for } y \rightarrow \infty \\
T=T_{\mathrm{a}} & \text { at } x=0 \\
u=v=0 & \text { at } y=0 \text { and } y \rightarrow \infty \\
u=v=0 & \text { at } x=0 .
\end{array}
$$

In examining equation (2) we note that the nonDarcy terms are:

(i) Inertia (convective) term: expected to be significant near the leading edge. Also, for $K \rightarrow \infty$, i.e. no rigid matrix present, this term results in the dependence of the Nusselt number on the Prandtl number and as a result $N u_{x}(P r \rightarrow \infty) / N u_{x}(P r \rightarrow 0)$ is nearly 2 .

(ii) Boundary term : enforces the no-slip condition at the wall. It causes lower velocities near the wall and, consequently, smaller heat transfer rates as shown in ref. [11].

(iii) Separation (velocity-squared) term: expresses the experimental results and accounts for the flow separation as it occurs in flow through the pores and over the rigid matrix. This results in smaller velocities

$\uparrow$ The vertical component of the pore velocity, $u$, is larger than Darcy's filter velocity by a factor of $1 / \varepsilon$, i.e. $u=u_{\mathrm{D}} / \varepsilon$. and, consequently, smaller heat transfer rates as shown in ref. [11].

\section{INTEGRAL APPROXIMATE SOLUTION}

As has been shown in ref. [11] the velocity profile changes with $\xi_{x}$ by moving from the conventional cubic form for $\xi_{x}=0$ to an exponential form for larger $\xi_{x^{*}}$ The exponential type profile overestimates the $N u_{x}$ by $40 \%$ at $\xi_{x}=0$ while resulting in the correct $N u_{x}$ for large $\xi_{x}$. The cubic form overpredicts the $N u_{x}$ by $7 \%$ for $\xi_{x}=0$ and underpredicts the $N u_{x}$ by $20 \%$ at large $\xi_{x}$. Here we choose the cubic form in favor of more accuracy at low $\xi_{x}$. This profile is

$$
u=U(x) y \delta^{-1}\left(1-y \delta^{-1}\right)^{2} .
$$

For temperature we have

$$
T=\left(1-y \delta^{-1}\right)^{2}
$$

which leads to

$$
N u_{x}=2 \times \delta^{-1}
$$

where it is assumed that the thermal and viscous boundary layer thicknesses are identical. The maximum velocity $U_{\text {pax }}$ is equal to $4(27)^{-1} U$ and takes place at $y=3^{-1} \delta$.

By applying $x, v_{\mathrm{f}} x^{-1}$, and $\left(T_{\mathrm{w}}-T_{\mathrm{a}}\right)$ to scale length, $\S$ velocity and temperature, we have

$$
\begin{gathered}
\frac{\partial u}{\partial x}+\frac{\partial v}{\partial y}=0 \\
u \frac{\partial u}{\partial x}+v \frac{\partial u}{\partial y}=\frac{\partial^{2} u}{\partial y^{2}}-\gamma_{x}^{2} u+G r_{x} T-\Psi u^{2} \\
u \frac{\partial T}{\partial x}+v \frac{\partial T}{\partial y}=P r^{-1} \frac{\partial^{2} T}{\partial y^{2}}
\end{gathered}
$$

Substitution of the above profiles into the integrated forms of equations (2a) and (3a) leads to

$$
\begin{gathered}
U^{2} \delta \frac{\mathrm{d}}{\mathrm{d} x} U^{2} \delta=-105 U^{3}-(105) 12^{-1} \gamma_{x}^{2} U^{3} \delta^{2} \\
+35 G r_{x} U^{2} \delta^{2}-\Psi U^{4} \delta^{2} \\
U \delta \frac{\mathrm{d}}{\mathrm{d} x} U \delta=P r^{-1} 60 U
\end{gathered}
$$

subject to $U(0)=\delta(0)=0$.

Equations (2b) and ( $3 b)$ were solved numerically [15] when necessary, and the singularities were avoided by applying the results for $\gamma_{x}=0$ over a small distance

$\ddagger$ In general, this depends on the Prandtl number. Some discussions are offered in ref. [14].

$\$$ In order to avoid confusion a length scale $L$ could be used instead of $x$, however, since in keeping with the literature the results will be presented based on $x$, this was not atlempted. The integrations have been performed by treating the length scale as a constant. 
$\Delta x$ at the initial part of the integration. Then, $\Delta x$ was reduced until the results no longer changed.

\section{PREDICTED RESULTS}

Assuming that the velocity profile remains the same even for lower permeabilities, the approximate integral method, along with the typical profiles, leads to differential equations for the maximum velocity and the boundary layer thickness. For low permeabilities some useful algebraic relations can be found.

\subsection{Low permeability}

Numerical experiments with equations (2b) and (3b) show that for Prandtl numbers near unity, $\xi_{x}>10$ and $\Psi=0$ (the results for $\Psi \neq 0$ are given in Appendix B) we have

or

$$
4^{-1} U \gamma_{x}^{2}=G r_{x}
$$

$$
U=4 \gamma_{x}^{-2} G r_{x} \text { for } \xi_{x}>10 .
$$

Consequently, the maximum velocity becomes $U_{\max }=16(27)^{-1} \gamma_{x}^{-2} G r_{x}$. Therefore, the maximum Reynolds number based on small length scale, i.e. $R e_{K}=U_{\max } x^{-1} K^{1 / 2} \varepsilon^{-1 / 2}$, is

$$
\begin{aligned}
R e_{K}=\frac{16}{27} & \frac{G r_{x}}{\gamma_{x}^{2}} x^{-1} K^{1 / 2} \varepsilon^{-1 / 2} \\
& =\frac{16}{27} \frac{g \beta}{v_{\mathrm{f}}^{2}}\left(T_{\mathrm{w}}-T_{\mathrm{a}}\right) K^{3 / 2} \varepsilon^{-3 / 2}=\frac{16}{27} \varepsilon^{-3 / 2} G r_{K}
\end{aligned}
$$

which is independent of $x$ and is generally less than unity. Therefore, for $\xi_{x}>10$ the velocity-squared term is not significant.

By applying equation (8) to equation ( $3 b$ ), we have

$$
\delta x^{-1}=30^{1 / 2}\left(y_{x}^{-2} \operatorname{Pr} G r_{x}\right)^{-1 / 2} \text { for } \xi_{x}>10 .
$$

The ratio of the boundary layer thickness when the rigid matrix is present to that in its absence is

$$
\frac{\Delta}{\Delta\left(\gamma_{x}=0\right)}=0.984 \operatorname{Pr}^{1 / 4}(1+0.952 P r)^{-1 / 4} \xi_{x}^{1 / 2} .
$$

The Nusselt number is

$$
N u_{x}=(2 / 15)^{1 / 2}\left(\gamma_{x}^{-2} \operatorname{Pr} G r_{x}\right)^{1 / 2} \text { for } \xi_{x}>10
$$

or

$2^{1 / 2} N u_{x} G r_{x}^{-1 / 4}=(8 / 15)^{1 / 2} \operatorname{Pr}^{1 / 2} \xi_{x}^{-1 / 2}$

$$
\text { for } \xi_{x}>10
$$

The result for the Nusselt number based on the velocity slip boundary condition given in refs. $[5,6$, 12] and also in $\Lambda$ ppendix $A$ is

$$
2^{1 / 2} N u_{x}^{-1 / 4} G r_{x}^{-1 / 4}=(4 / 5)^{1 / 2} \operatorname{Pr}^{1 / 2} \xi_{x}^{-1 / 2} .
$$

When compared, equation (11a) results in a Nusselt number $20 \%$ smaller than that given by equation (12). This is due to the no-slip boundary condition and the velocity profile assumed here. This difference is similar to that found in ref. [11].

\subsection{Intermediate permeability}

5.2.1. Inertia and boundary terms. For any combination of $\gamma_{x}, G r_{x}, \Psi$, and $P r$, equations (2b) and (3b) can be solved to obtain the Nusselt number. The results for $\operatorname{Pr}=0.7$ and $\Psi=0$ are given in Fig. 3. The results for various values of $G r_{x}$ all fall on the same line when the values of $2^{1 / 2} N u_{x} G r_{x}^{-1 / 4}$ rather than $N u_{x}$ are plotted vs $\xi_{x}$. The results for no inertia and boundary terms are also shown. The inclusion of these terms results in a lower Nusselt number, as expected. This trend is similar to that found in refs. $[10,11]$. As was mentioned, for $\xi_{x}>10$ the inertia and boundary terms are not significant.

5.2.2. Velocity-squared term. As an example of the significance of the non-Darcy effects, consider the case

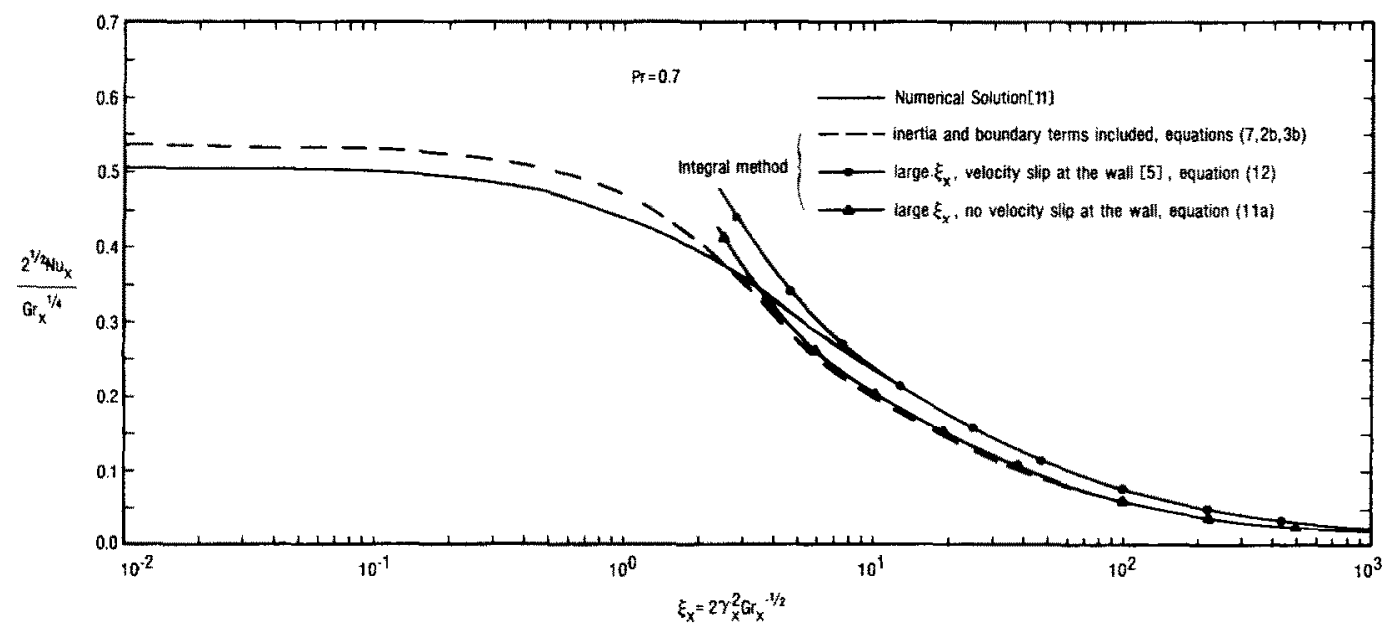

FIG. 3. The results of the integral approximate method, for Nusselt number, when the inertia and boundary terms are either included or excluded. The results are for $P r=0.7$. 
Table 2. Examples of the effect of the velocity-squared term on the heat transfer rate

\begin{tabular}{|c|c|c|c|c|c|c|c|c|c|c|c|c|c|}
\hline \multirow{3}{*}{$\frac{\text { Fluid }}{\begin{array}{c}g \beta / \nu_{f}^{2} \\
\left(\mathrm{~m}^{-3} \mathrm{~K}^{-1}\right)\end{array}}$} & \multirow{2}{*}{\multicolumn{4}{|c|}{ Geometry }} & & & & & \multicolumn{3}{|c|}{$\begin{array}{l}\text { Secondary dimensionless } \\
\text { parameters }\end{array}$} & \multirow[b]{3}{*}{$\frac{2^{1 / 2} N u_{x}}{G r_{x}^{1 / 4}}$} & \multirow[b]{3}{*}{$\frac{N u_{x}}{N u_{x}(\Psi=0)}$} \\
\hline & & & & & \multicolumn{4}{|c|}{$\begin{array}{c}\text { Primary dimensionless } \\
\text { parameters }\end{array}$} & \multirow{2}{*}{$\frac{\begin{array}{c}\text { Boundary and } \\
\text { inertia }\end{array}}{\xi_{x}}$} & \multicolumn{2}{|c|}{$\begin{array}{l}\text { Velocity } \\
\text { squared }\end{array}$} & & \\
\hline & $\begin{array}{l}\Delta T \\
(\mathrm{~K})\end{array}$ & $\begin{array}{c}x \\
(\mathrm{~m})\end{array}$ & $\varepsilon \dagger$ & $\underset{\left(\mathrm{m}^{2}\right)}{K \dagger} F \dagger$ & $G r_{x}$ & $\gamma_{x}^{2}$ & $\Psi_{x}$ & $\operatorname{Pr}_{\mathrm{e}} \ddagger$ & & $G r_{k}$ & $\operatorname{Re}_{k} \delta$ & & \\
\hline \multirow[t]{13}{*}{$10^{8}$} & 100 & 0.1 & 0.9 & $10^{-5} 0.01$ & $10^{7}$ & $10^{3}$ & 0.3 & 0.7 & 0.6 & $3 \times 10^{2}$ & 34 & 0.473 & 0.96 \\
\hline & & & & $10^{-6}$ & & $10^{4}$ & 1 & & 6 & 10 & 3.8 & 0.246 & 0.99 \\
\hline & & & & $10^{-5} 0.05$ & & $10^{3}$ & 1.6 & & 0.6 & $3 \times 10^{2}$ & 30 & 0.422 & 0.85 \\
\hline & & & & $10^{-6}$ & & $10^{4}$ & 5 & & 6 & 10 & 3.2 & 0.229 & 0.92 \\
\hline & & & & $10^{-7}$ & & $10^{5}$ & 16 & & 60 & 0.3 & 0.13 & 0.0767 & 0.97 \\
\hline & & & & $10^{-5} 0.1$ & & $10^{3}$ & 3 & & 0.6 & $3 \times 10^{2}$ & 25 & 0.384 & 0.78 \\
\hline & & & & $10^{-6}$ & & $10^{4}$ & 10 & & 6 & 10 & 3.0 & 0.215 & 0.86 \\
\hline & & & & $10^{-7}$ & & $10^{5}$ & 30 & & 60 & 0.3 & 0.13 & 0.0745 & 0.94 \\
\hline & & & & $10^{-8}$ & & $10^{6}$ & $10^{2}$ & & $6 \times 10^{2}$ & $10^{-2}$ & $4.1 \times 10^{-3}$ & 0.0243 & 0.98 \\
\hline & & & & $10^{-5} 0.5$ & & $10^{3}$ & 16 & & 0.6 & $3 \times 10^{2}$ & 14 & 0.264 & 0.53 \\
\hline & & & & $10^{-6}$ & & $10^{4}$ & 50 & & 6 & 10 & 2.0 & 0.170 & 0.68 \\
\hline & & & & $10^{-7}$ & & $10^{5}$ & $1.6 \times 10$ & & 60 & 0.3 & 0.12 & 0.0745 & 0.94 \\
\hline & & & & $10^{-8}$ & & $10^{6}$ & $5 \times 10^{2}$ & & $6 \times 10^{2}$ & $10^{-2}$ & $4.1 \times 10^{-3}$ & 0.0243 & 0.98 \\
\hline
\end{tabular}

†For some foams. In these media $F$ decreases as $K$ increases, also generally $K<10^{-6} \mathrm{~m}^{2}$.

$\$$ Generally varies with $\varepsilon$ and $K$.

$\S$ Both $F$ and $R e_{K}$ are needed in order to determine the significance of the velocity-squared term.

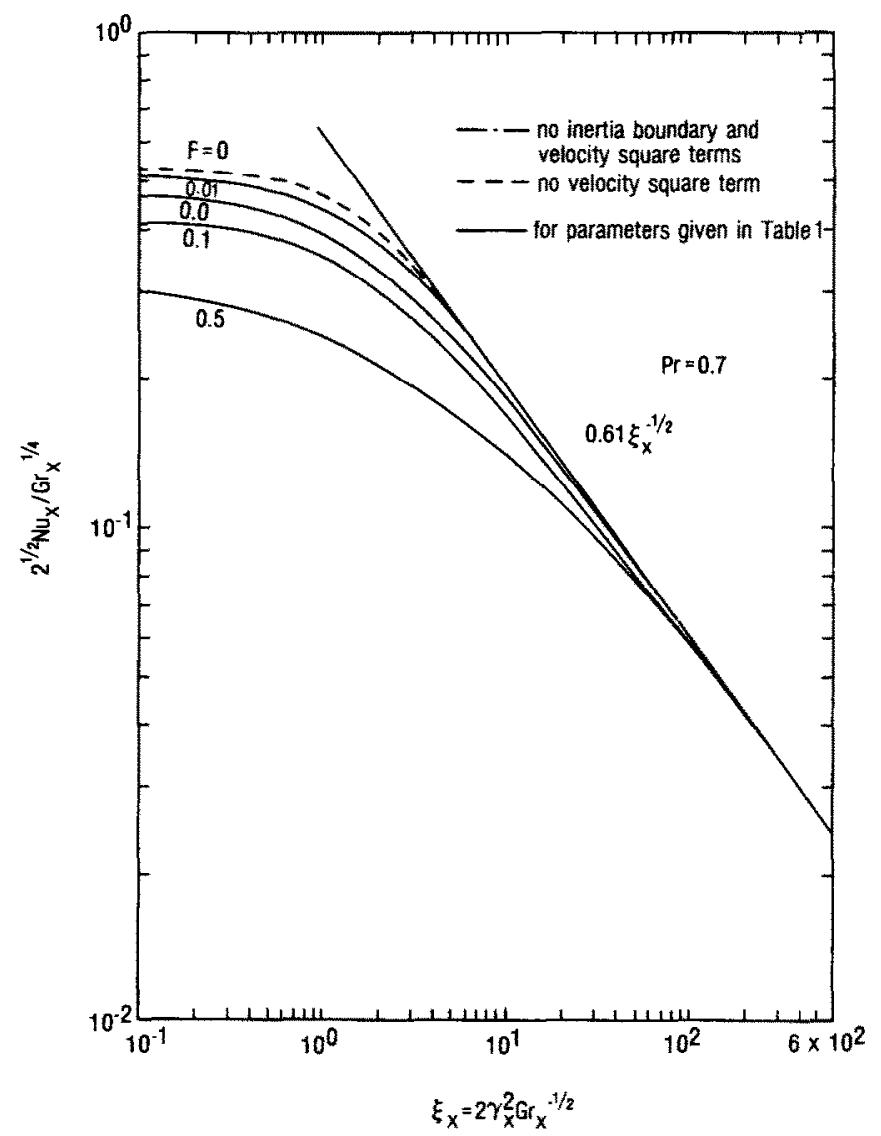

FiG. 4. The effect of the velocity-squared term on the Nusselt number for $G r_{x}=10^{7}$ and $\mathrm{Pr}=0.7$. 


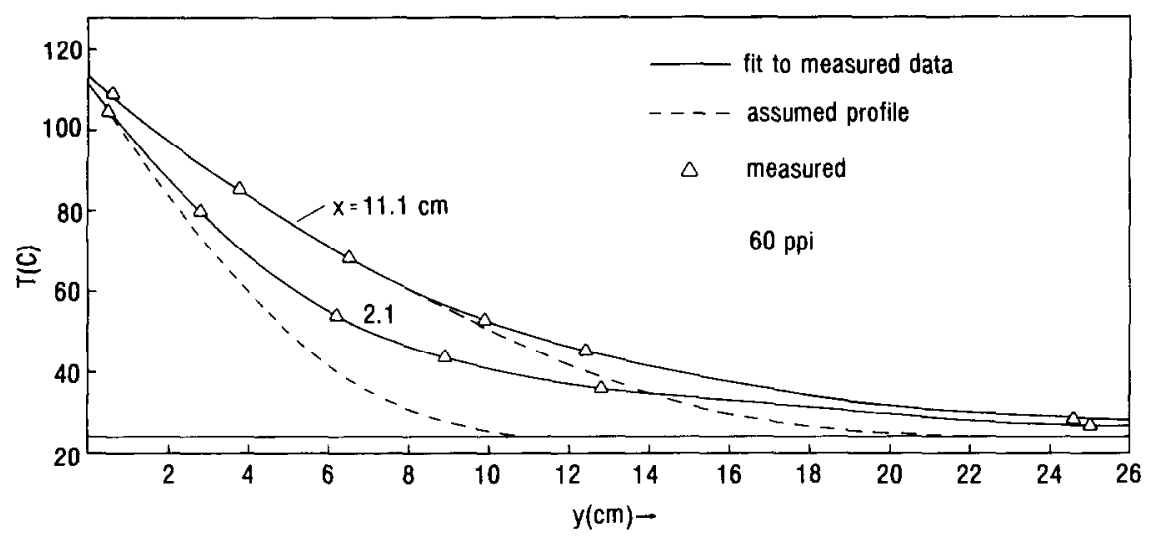

Fig. 5. Measured and assumed temperature distributions inside the $60 \mathrm{ppi}$. Polyurethane foam at two different vertical locations.

of $\operatorname{Pr}=0.7$ and $G r_{x}=10^{7}$. Table 2 gives the typical values for $K, \varepsilon$, and $F$ for foams except for $F=0.5$ which is unrealistically high and is included as an example of an extreme case. The results are plotted in Fig. 4. Equation (11a) which is valid for $\xi_{x}>10$ is also plotted. Again, even for large values of $F$ the nonDarcy effects are not significant for $\xi_{x}>10$.

\section{COMPARISON BETWEEN THE EXPERIMENTAL AND PREDICTED RESULTS}

Figure 5 shows the temperature distributions for two different locations for the $60 \mathrm{ppi}$ foam. The results for other ppi's and locations were similar to these.
Shown along with the experimental results are the profile results given by equation (6) when $\delta$ was calculated from equation (9). In general, the secondorder profile gives a smaller boundary layer thickness than the similarity solution. Therefore, it is expected that the more exact numerical solutions as given in ref. [11] would result in better agreement with experimental results. However, for the prediction of the heat transfer rate, the integral method is sufficiently accurate and also convenient.

Table 3 gives the experimental results for the five different foams used. Figure 6 shows the experimental results obtained in this study as well as the similarity solution of ref. [5]. In general, there is good agreement

Table 3. The experimental conditions and results for the five porous media studied

\begin{tabular}{|c|c|c|c|c|c|c|c|c|c|c|}
\hline ppi & $\begin{array}{c}K \\
\left(\mathrm{~m}^{2}\right)\end{array}$ & $\left(\begin{array}{c}k_{\mathrm{e}} \\
\left(\mathrm{W} \mathrm{m} \mathrm{m}^{-1} \mathrm{~K}^{-1}\right)\end{array}\right.$ & $\begin{array}{c}x \\
(\mathrm{~cm})\end{array}$ & $\begin{array}{c}T_{\mathrm{a}} \\
\left({ }^{\circ} \mathrm{C}\right)\end{array}$ & $P r_{\mathrm{e}}$ & $\begin{array}{c}T_{w} \\
\left({ }^{\circ} \mathrm{C}\right)\end{array}$ & $R a_{x}$ & $\gamma_{x}^{2}$ & $\xi_{x}$ & $N u_{x}$ \\
\hline \multirow[t]{8}{*}{10} & $1.6 \times 10^{-7}$ & 0.0619 & 1.0 & 23.61 & 0.333 & 81.05 & $1.641 \times 10^{3}$ & $6.124 \times 10^{2}$ & $1.744 \times 10^{1}$ & 0.652 \\
\hline & & & 2.0 & & & 81.81 & $1.313 \times 10^{4}$ & $2.450 \times 10^{3}$ & $2.467 \times 10^{1}$ & 0.790 \\
\hline & & & 3.5 & & & 81.76 & $7.036 \times 10^{4}$ & $7.502 \times 10^{3}$ & $3.263 \times 10^{1}$ & 1.140 \\
\hline & & & 5.0 & & & 81.01 & $2.051 \times 10^{5}$ & $1.531 \times 10^{4}$ & $3.901 \times 10^{1}$ & 1.127 \\
\hline & & & 7.0 & & & 81.25 & $5.629 \times 10^{5}$ & $3.001 \times 10^{4}$ & $4.615 \times 10^{1}$ & 1.626 \\
\hline & & & 8.0 & & & 80.99 & $8.402 \times 10^{5}$ & $3.920 \times 10^{4}$ & $4.934 \times 10^{1}$ & 1.775 \\
\hline & & & 9.5 & & & 81.29 & $1.407 \times 10^{6}$ & $5.528 \times 10^{5}$ & $5.376 \times 10^{1}$ & 1.778 \\
\hline & & & 11.0 & & & 81.45 & $2.184 \times 10^{6}$ & $7.413 \times 10^{4}$ & $5.785 \times 10^{1}$ & 2.059 \\
\hline \multirow[t]{4}{*}{45} & $3.2 \times 10^{-8}$ & 0.0396 & 2.1 & 23.02 & 0.529 & 104.98 & $2.977 \times 10^{4}$ & $1.338 \times 10^{4}$ & $1.128 \times 10^{2}$ & 0.564 \\
\hline & & & 5.1 & & & 105.24 & $4.264 \times 10^{5}$ & $7.893 \times 10^{4}$ & $1.759 \times 10^{2}$ & 0.876 \\
\hline & & & 8.1 & & & 105.51 & $1.708 \times 10^{6}$ & $1.990 \times 10^{5}$ & $2.216 \times 10^{2}$ & 0.988 \\
\hline & & & 11.1 & & & 105.02 & $4.396 \times 10^{6}$ & $3.738 \times 10^{5}$ & $2.594 \times 10^{2}$ & 1.08 \\
\hline \multirow[t]{4}{*}{60} & $1.6 \times 10^{-8}$ & 0.0389 & 2.1 & 24.12 & 0.532 & 112.84 & $2.886 \times 10^{4}$ & $2.701 \times 10^{4}$ & $2.320 \times 10^{2}$ & 0.389 \\
\hline & & & 5.1 & & & 113.10 & $4.133 \times 10^{5}$ & $1.593 \times 10^{5}$ & $3.616 \times 10^{2}$ & 0.687 \\
\hline & & & 8.1 & & & 113.24 & $1.656 \times 10^{6}$ & $4.019 \times 10^{5}$ & $4.557 \times 10^{2}$ & 0.819 \\
\hline & & & 11.1 & & & 113.09 & $4.261 \times 10^{6}$ & $7.547 \times 10^{5}$ & $5.335 \times 10^{2}$ & 0.988 \\
\hline \multirow[t]{4}{*}{80} & $7.8 \times 10^{-9}$ & 0.0360 & 2.1 & 23.90 & 0.575 & 116.81 & $3.262 \times 10^{4}$ & $5.540 \times 10^{4}$ & $4.653 \times 10^{2}$ & 0.300 \\
\hline & & & 5.1 & & & 117.09 & $4.672 \times 10^{5}$ & $3.268 \times 10^{5}$ & $7.251 \times 10^{2}$ & 0.553 \\
\hline & & & 8.1 & & & 116.92 & $1.872 \times 10^{6}$ & $8.244 \times 10^{5}$ & $9.139 \times 10^{2}$ & 0.695 \\
\hline & & & 11.1 & & & 117.34 & $4.817 \times 10^{6}$ & $1.548 \times 10^{6}$ & $1.070 \times 10^{3}$ & 0.954 \\
\hline \multirow[t]{4}{*}{100} & $3.7 \times 10^{-9}$ & 0.0346 & 2.1 & 24.09 & 0.598 & 117.21 & $3.396 \times 10^{4}$ & $1.168 \times 10^{5}$ & $9.806 \times 10^{2}$ & 0.273 \\
\hline & & & 5.1 & & & 117.45 & $4.864 \times 10^{5}$ & $6.887 \times 10^{5}$ & $1.528 \times 10^{3}$ & 0.449 \\
\hline & & & 8.1 & & & 117.02 & $1.949 \times 10^{6}$ & $1.738 \times 10^{6}$ & $1.926 \times 10^{3}$ & 0.583 \\
\hline & & & 11.1 & & & 117.34 & $5.014 \times 10^{6}$ & $3.264 \times 10^{6}$ & $2.255 \times 10^{3}$ & 0.798 \\
\hline
\end{tabular}




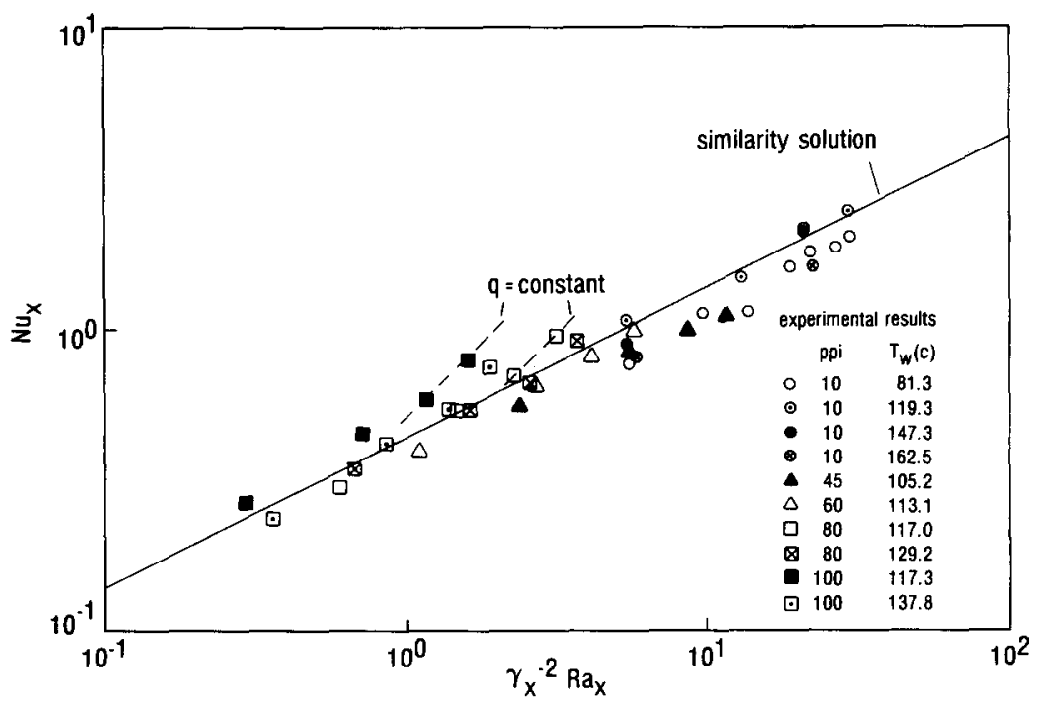

Fig. 6. Variations of the local heat transfer rates with the modified local Rayleigh number for the five different foams used.

between the measurements and predictions. However, for low permeability media the $P \dot{e}$ is relatively small and the finiteness of the foam blocks affects the heat transfer rate through axial conditions.

Figure 7 shows the experimental results along with the predicted results that include the non-Darcy effects. As was mentioned the range of $\xi_{x}$ encountered in this study is beyond the values for which the nonDarcy effects are significant. Also, the integral solution underpredicts $N u_{x}$ by $20 \%$ for large $\xi_{x}$. In order to include the velocity-squared term, $F, x$, and $G r_{x}$ must be specified. The integral solutions are for $F=0.1, x=10 \mathrm{~cm}$ and $G r_{x}=10^{7}$. The low Pé effect mentioned above is more clearly demonstrated in Fig. 7. For free convection from a vertical plate, $q$ is proportional to $x^{a}$, where $a=-1 / 4$ for no rigid matrix present and $a=-1 / 2$ for the Darcian regime.

In general, the experimental results are in closer agreement with the predicted results which are for $\operatorname{Pr}=0.7$ and 0.35 and also include the velocitysquared term.

In order to achieve still lower $\xi_{x}, \Delta T$ was further increased. However, the decrease in $\beta_{\mathrm{f}}$ and the increase in $v_{\mathrm{f}}$, with an increase in temperature, approximately compensated for the increase in $\Delta T$. Therefore, no further increase in $\xi_{x}$ was possible. Also, for

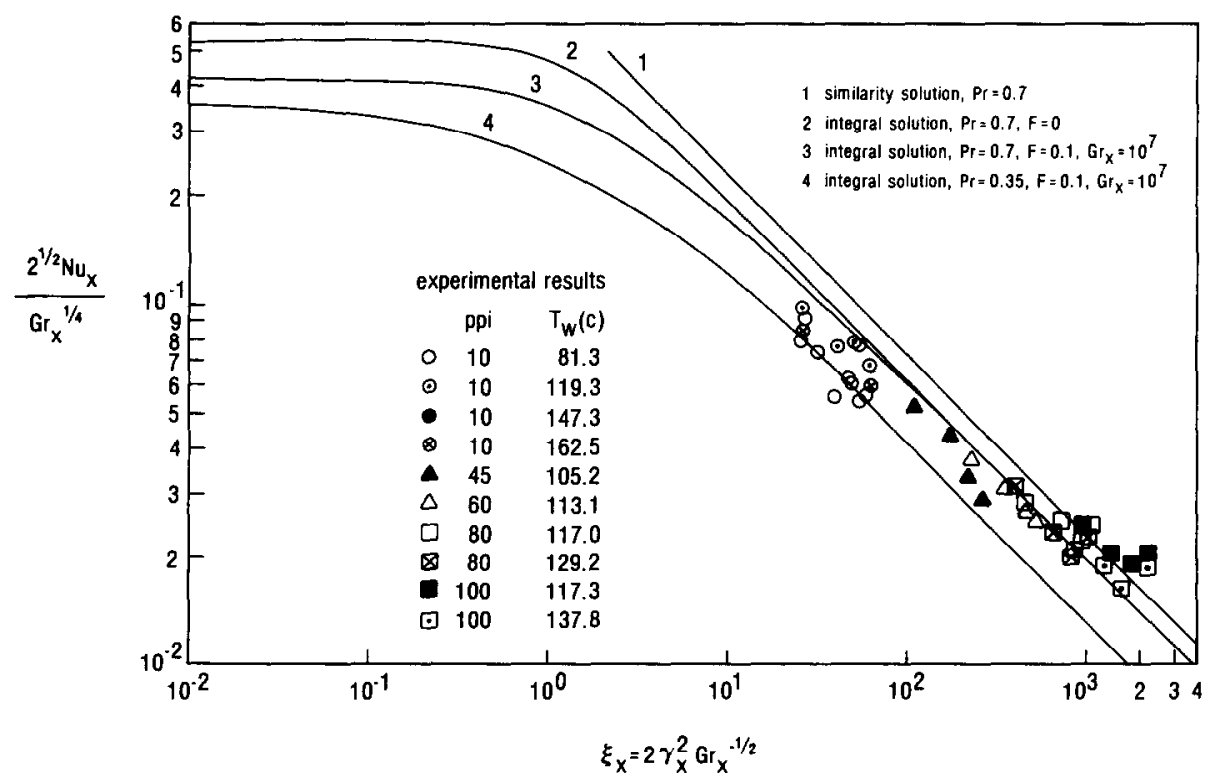

FIG. 7. Variation of the local heat transfer rate with respect to $\xi_{x}$. The solid lines are the predictions. 
$T_{\mathrm{w}}>160^{\circ} \mathrm{C}$ the foam began to blacken and deform, and the latter leads to a change in permeability for the portion of the foam adjacent to the wall.

Note that in order to keep

$$
\xi_{x}=\frac{2 \varepsilon}{K}\left[\frac{v_{\mathrm{f}}^{2} x}{g \beta_{\mathrm{f}}\left(T_{\mathrm{w}}-T_{\mathrm{a}}\right)}\right]^{1 / 2}
$$

small, $K$ and $T_{\mathrm{w}}-T_{\mathrm{a}}$ must be large and $x$ needs to be small. The value of $x$ must be taken such that the nonboundary layer type flow at the leading edge is not included. Therefore, in our experiments, the boundary and development effects in the momentum equation are significant only over a short distance from the leading edge. Considering the relatively large $K$ and $T_{\mathrm{w}}-T_{\mathrm{a}}$ encountered in these experiments, for air as the fluid and under moderate temperature and pressure conditions, the flow is Darcian over most of the plate.

\section{SUMMARY}

The approximate results for natural convection from a vertical plate imbedded in porous media show that for gases and for $\xi_{x}=2 \gamma_{x}^{2} G r_{x}^{-1 / 2}>10$ the nonDarcy effects are not significant. For $\xi_{x}<10$ all of these effects can be significant.

Experiments have been conducted for high permeability media and for large ranges of buoyancy potential; however, comparison with the predicted results shows that all the experimental results are in the Darcian regime. Good agreement has been found for relatively high permeability media. For lower permeabilities, the Péclet number is small and the effect of axial conduction becomes significant.

\section{REFERENCES}

1. G. S. Beavers and E. M. Sparrow, Non-Darcy flow through fibrous porous media, J. Appl. Mech. 36, 711714 (1969).

2. J. C. Koh, J. L. Dutton, B. A. Benson and A. Fortini, Friction factor for isothermal and nonisothermal flow through porous media, ASME J. Heat Transfer 99, 367373 (1977).

3. K. Vafai and C. L. Tien, Boundary and inertia effects on flow and heat transfer in porous media, Int. J. Heat Mass Transfer 24, 195-203 (1981).

4. M. Kaviany, Laminar flow through a porous channel bounded by isothermal parallel plates, Int.J. Heat Mass Transfer 28, 851-858 (1985).

5. P. Cheng and W. J. Minkowycz, Free convection about a vertical that plate embedded in a porous medium with application to heat transfer from a dike, J. Geophys. Res. 82, 2040-2044 (1977).

6. P. Cheng and C. T. Hsu, Higher-order approximations for Darcian free convection flow about a semi-infinite vertical plate, ASME J. Heat Transfer 106, 143-151 (1984).

7. Y. Joshi and B. Gebhart, Vertical natural convection flows in porous media : calculations of improved accuracy, Int. J. Heat Mass Transfer 27, 69-75 (1984).

8. A. Bejan and D. Poulikakos, The non-Darcy regime for vertical boundary layer natural convection in a porous medium, Int. J. Heat Mass Transfer 27, 717-722 (1984)

9. O. A. Plumb and J. C. Huenefeld, Non-Darcy natural convection from heated surfaces in saturated porous media, Int. J. Heat Mass Transfer 24, 765-768 (1981).

10. G. H. Evans and O. A. Plumb, Natural convection from a vertical isothermal surface imbedded in a saturated porous media, ASME Paper No. 78-HT-85 (1978).

11. J. T. Hong, C. L. Tien and M. Kaviany, Non-Darcian effects on vertical plate natural convection in porous media with high porosity, Int. J. Heat Mass Transfer 28. 2149-2157 (1985).

12. P. Cheng and C. L. Ali, An experimental investigation of free convection about a heated inclined surface in a porous medium, ASME Paper No. 81-HT-85 (1981).

13. P. Cheng, Convective heat transfer in porous layers by integral method, Lett. Heat Mass Transfer 5, 243-252 (1978).

14. A. J. Ede, Advances in free convection. In Advances in Heat Transfer (Edited by J. P. Hartnett and T. F. Irvine), Vol. 4, pp. 1-64. Academic Press, New York (1967)

15. H. J. Romanelli, Numerical integration methods for the solution of ordinary differential equations. In Mathematical Methods for Digital Computers (Edited by A. Ralston and H. S. Wilf), pp. 110-120. Wiley, New York (1960).

\section{APPENDIX A}

An exponential type profile (due to a no-slip boundary condition) is used by many investigators. By assuming the following velocity profile (similar to that for temperature)

$$
u=U(x)\left(1-y \delta^{-1}\right)^{2}
$$

and applying it to equations $(2 b)-(3 b)$ and dropping the inertia and boundary terms, we have

$$
\begin{gathered}
U=\gamma_{x}^{-2} G r_{x} \\
\delta x^{-1}=20^{1 / 2}\left(\gamma_{x}^{-2} \operatorname{Pr} G r_{x}\right)^{-1 / 2}
\end{gathered}
$$

and

$$
N u_{x}=5^{-1 / 2}\left(\gamma_{x}^{-2} \operatorname{Pr} G r_{x}\right)^{1 / 2}
$$

which are the same as those given in ref. [13].

\section{APPENDIX B}

Assuming that the inertia and boundary terms are negligible but including the velocity-squared term from equation (2b), we have

$$
\Psi U^{2}+\frac{105}{12} \gamma_{x}^{2} U-35 G r_{x}=0
$$

which leads to

$U=\left[-\frac{105}{12} \gamma_{x}^{2}+\left(\frac{105^{2}}{12^{2}} \gamma_{x}^{4}+140 \Psi G r_{x}\right)^{1 / 2}\right] / 2 \Psi$

$\Psi \neq 0$.

The Nusselt number, which is equal to $\left(30^{-1} \operatorname{Pr} U\right)^{1 / 2}$, then becomes

$$
\frac{2^{1 / 2} N u_{x}}{G r_{x}^{1 / 4}}=\left\{\frac{P r}{60 \Psi}\left[-\frac{105}{12} \gamma_{x}^{2}+\left(\frac{105^{2}}{12^{2}} \gamma_{x}^{4}+140 \Psi G r_{x}\right)^{1 / 2}\right]\right\}^{1 / 2}
$$

These results are similar to those found in ref. [8] using the exponential type velocity profile. 


\title{
CONVECTION THERMIQUE NATURELLE ENTRE UNE PLAQUE VERTICALE ET UN
} MILIEU A FORTE PERMEABILITE: EXPERIENCE ET SOLUTION APPROCHEE

Résumé - On étudie expérimentalement et analytiquement le transfert thermique entre une plaque verticale isotherme et un milieu adjacent à haute perméabilité. Le milieu utilisé est une mousse de polyurethane saturée d'air. Une méthode intégrale est appliquée pour calculer le transfert en incluant les effets non darciens qui sont supposés être actifs pour les hautes perméabilités et les grands nombres de Rayleigh. Un bon accord est trouvé entre les résultats de l'expérience et du calcul sauf quand la perméabilité est relativement faible et que le nombre de Péclet devient très petit. Bien que les perméabilités rencontrées sont grandes dans les conditions de l'expérience les nombres de Rayleigh ne sont pas très élevés; par suite les effets non darciens ne sont pas sensibles.

\section{WÄRMEÜBERGANG INFOLGE NATÜRLICHER KONVEKTION VON EINER SENKRECHTEN PLATTE AN MEDIEN HOHER PERMEABILITÄT: EXPERIMENTELLE UNTERSUCHUNG UND NÄHERUNGSLOOSING}

Zusammenfassung-Es wurde der Wärmeübergang von einer isothermen, senkrechten Platte an gesättigte poröse Medien von hoher Permeabilität experimentell und analytisch untersucht. Als Medien wurden Polyurethan-Schäume verwendet. Für die Berechnung des Wärmeübergangs wird eine Integrl-Methode unter Einbeziehung der' Nicht-Darcy-Effekte verwendet, deren signifikanter Einfluß bei hohen Permeabilitäten und hohen Rayleigh-Zahlen angenommen wird. Außer für niedrige Permeabilität und hohe Peclet-Zahlen wurde eine gute Ubbereinstimmung zwischen Rechnung und Messung erzielt. Obwohl bei einigen Schäumen die Permeabilität groß war, ergaben sich bei den experimentellen Bedingungen in dieser

Untersuchung nicht sehr hohe Rayleigh-Zahlen, so daB die Nicht-Darcy-Effekte ohne Bedeutung sind.

\section{ТЕПЛООБМЕН ПРИ ЕСТЕСТВЕННОЙ КОНВЕКЦИИ ВЕРТИКАЛЬНОЙ ПЛАСТИНЫ СО СРЕДОЙ ВЫСОКОЙ ПРОНИЦАЕМОСТИ: ЭКСПЕРИМЕНТ И ПРИБЛИЖЕННОЕ PEWEHИЕ}

\begin{abstract}
Amотапи-Экспериментально и аналитически изучается интенсивность теплообмена изотермической вертикальной пластины, контактирукщей с насыщенной пористой средой с высокой проницаемостью. В качестве среды использовались полиуретановые пластины, заполненные воздухом. Интегральный метод пркменялся для расчета коэффициента теплообмена, а также жффектов, не подчиняющихся закону Дарси, которые предполагаются существенными при высоких проницаемостях и болыших числах Рэлея. Найдено хорощее совпадение между экспериментальными и расчетными данными за исключением случап, когда проницаемость относительно низка и число Пекле становится очень малым. Хотя некоторые из встречающихся материалов обладают большой проницаемостью, в настоящих опытах чнсла Рэлея были не очень высоки, поэтому зффекты откпонени от закона Дарси оказались незначитепьны.
\end{abstract}

